\title{
Análise da contribuição ambiental por meio da alteração da matriz energética do setor brasileiro de ferro-gusa e aço
}

\author{
Assessment of the environmental contribution by changing the \\ energy matrix of the brazilian pig iron and steel sector
}

\author{
Flávia de Castro Camioto ${ }^{1}$ \\ Daisy Aparecida do Nascimento Rebelatto ${ }^{2}$
}

\begin{abstract}
Resumo: O objetivo deste artigo é analisar a possibilidade de contribuição ambiental por meio da alteração da matriz energética do setor industrial de ferro-gusa e aço. Para a medição das emissões de $\mathrm{CO}_{2}$ dos combustíveis utilizados, nesse setor, foi usado o método top-down, proposto pelo IPCC. Além disso, a partir dos dados de consumo energético, foi realizada a quantificação das emissões de $\mathrm{CO}_{2}$ supondo a mudança da matriz energética desse setor para efeito de comparação das emissões. Os resultados deste estudo indicam que o coque de carvão mineral é responsável por 44,5\% do total de dióxido de carbono emitido por esse setor. Da mesma forma, se fosse possível utilizar somente um combustível na indústria de ferro-gusa e aço, para suprir sua demanda energética, as emissões de $\mathrm{CO}_{2}$ seriam menores para os combustíveis gasosos, líquidos e o alcatrão e outras fontes secundárias do petróleo. Apesar de o estudo ter indicado que o carvão vegetal é o segundo maior emissor de $\mathrm{CO}_{2}$ do setor, o mesmo pode contribuir para a redução do aquecimento global, desde que este energético seja proveniente de matas de reflorestamento destinadas para a atividade industrial.
\end{abstract}

Palavras-chave: Setor de ferro gusa e aço. Método top down. Energia renovável. GEE.

\begin{abstract}
In a period of climate change and increased emission restrictions, it is important to focus on developing nations headed towards a low-carbon economy. The purpose of this article is to analyze the potential environmental contribution that a change in the energy matrix of the pig iron and steel sector may provide. For the measurement of $\mathrm{CO}_{2}$ emissions for each major fuel used in this sector, the Top-Down method proposed by the IPCC was used. Moreover, according to the data of energy consumption of the sector, a measurement of $\mathrm{CO}_{2}$ emissions was made supposing a change of the energy matrix for purposes of comparing the emission levels. The results of this study indicate that coking coal fuel accounts for $53.7 \%$ of the total carbon dioxide emitted by this sector. Furthermore, if it were possible to use only one fuel in the pig iron and steel sector to supply its energy demand, $\mathrm{CO}_{2}$ emissions would be lower for sources of gaseous and liquid fuels, tar, and other oil secondary sources. Although the study indicated that charcoal is the second largest emitter of $\mathrm{CO}_{2}$ in this sector, it can contribute to reducing global warming, as long as this energy comes from reforestation forests for this industrial activity.
\end{abstract}

Keywords: Pig Iron and Steel Sector. Top Down method. Renewable Energy. GHG.

\section{Introdução}

Num período de mudanças climáticas e restrições cada vez maiores a emissões, é importante focar o desenvolvimento das nações na direção de uma economia de baixo carbono. Em 1992, no Rio de Janeiro, foi realizada a Conferência das Nações Unidas sobre o Meio Ambiente e o Desenvolvimento, na qual a relação entre meio ambiente e desenvolvimento e a necessidade imperativa para o desenvolvimento sustentável foi reconhecida.
Os resultados apresentados no último relatório do Painel Intergovernamental sobre Mudanças Climáticas (INTERGOVERNMENTAL..., 2007) confirmam que as causas do aquecimento global são atribuídas, em grande parte, às atividades humanas, principalmente àquelas relacionadas à emissão de $\mathrm{CO}_{2}$. Da mesma forma, mostrou-se que as queimas de combustíveis fósseis são responsáveis por cerca de $90 \%$ das emissões antropogênicas de dióxido de carbono produzidas por ano.

\footnotetext{
${ }^{1}$ Instituto de Ciências Tecnológicas e Exatas - ICTE, Universidade Federal do Triângulo Mineiro - UFTM, Av. Doutor Randolfo Borges Júnior, 1250, CEP 38064-200, Uberaba, MG, Brasil, e-mail: flaviacamioto@ yahoo.com.br

${ }^{2}$ Escola de Engenharia de São Carlos - EESC, Universidade de São Paulo - USP, Av. Trabalhador são-carlense, 400, CEP 13566-590, São Carlos, SP, Brasil, e-mail: daisy@ @sc.usp.br
} 
Silva e Guerra (2009), no entanto, explicam que o uso desse combustível tem movido a economia mundial desde a Revolução Industrial, sendo que a energia é um dos componentes essenciais para o desenvolvimento social e econômico de uma nação, e seu suprimento é um pré-requisito fundamental às atividades humanas.

No que diz respeito aos sistemas produtivos, Glavic e Lukman (2007) apresentam o conceito de produção sustentável como sendo a criação de bens através de processos e sistemas que são não poluentes, que conservam energia e recursos naturais de forma economicamente viável, segura e saudável para os funcionários, comunidades e consumidores e que são socialmente e criativamente gratificantes para todas as partes interessadas no curto e longo prazo.

Nesse sentido, as implicações ambientais da produção e do uso dos recursos energéticos têm-se apresentado como um grande desafio aos países desenvolvidos e em desenvolvimento, uma vez que a produção, distribuição, transformação e consumo de energia devem ser orientados de modo a garantir o desenvolvimento, sem ampliar os efeitos negativos à sociedade e ao meio ambiente. Nesse sentido, alguns autores, como Lior (2010), enfatizam que é preciso um sistema político para suportar de forma rápida e efetiva movimentos em direção à energia sustentável.

Segundo Goldemberg e Moreira, (2005), a presença do governo é essencial para: 1) atender a demanda da sociedade por mais e melhores serviços de energia; 2) estimular a participação de fontes energéticas sustentáveis e duradouras; 3) priorizar o uso eficiente da energia para liberar capital aos setores mais produtivos da economia e preservar o meio ambiente; 4) utilizar o investimento em energia como fonte de geração de empregos e de estímulo à indústria nacional; 5) incorporar à matriz energética insumos importados quando isso resultar em vantagens comerciais e sociais ao país, inclusive através da abertura de exportação de produtos e serviços, e 6) produzir energia de diversas fontes, reduzindo o risco da eventual escassez de algumas delas de forma compatível com as reservas disponíveis no país.

Considerando esse contexto, em 1992 foi realizada a Convenção - Quadro das Nações Unidas sobre Mudança do Clima. A Convenção reconhece que a maior parcela das emissões de GEE é originária dos países desenvolvidos e que as emissões per capita dos países em desenvolvimento ainda são relativamente baixas. No entanto, ela reconhece, ainda, que a parcela de emissões originárias desses países crescerá para que eles possam satisfazer suas necessidades sociais e de desenvolvimento. $\mathrm{O}$ artigo 4.1 dessa Convenção estabeleceu obrigações comuns a todas as Partes da Convenção, levando em conta as responsabilidades comuns, mas diferenciadas dos países e suas prioridades de desenvolvimento nacional e regional, objetivos e circunstâncias. Entre as obrigações das Partes para com a Convenção está a formulação e implementação de programas nacionais e, conforme o caso, regionais, que incluam medidas para mitigar a mudança global do clima (BRASIL, 2010). Esse compromisso é em termos gerais e não está relacionado a nenhum objetivo específico para a redução das emissões de gases de efeito estufa.

Apesar de o Brasil não ser uma das Partes da Convenção, e como tal não ter compromissos obrigatórios para com ela, tem implementado uma série de medidas no setor energético, ao longo do tempo, que resultaram em menores emissões de $\mathrm{CO}_{2}$.

No entanto, Niu et al. (2011) concluíram em seu estudo que embora os países em desenvolvimento possam reduzir suas emissões de $\mathrm{CO}_{2}$ por unidade de consumo energético, o consumo total de energia irá aumentar rapidamente com o desenvolvimento econômico. Desse modo, esses países devem determinar uma forma de promover o crescimento econômico enquanto conservam energia e reduzem emissões.

No caso do Brasil, de acordo com Freitas e Kaneko (2011), a atividade econômica juntamente com a pressão demográfica são as principais forças que explicam o aumento das emissões. Por outro lado, a redução da intensidade de carbono e a diversificação da matriz energética para fontes mais limpas são os principais fatores que contribuem para mitigação de emissões.

Paz, Silva e Rosa (2007), que discutiram os conceitos de sustentabilidade e ética na política energética brasileira e suas implicações sociais e ambientais, afirmam que é imprescindível que a dinâmica das atividades econômicas para suprir as necessidades humanas pondere os fatores naturais limitantes, como condições para a produção, transformação, distribuição e consumo de energia.

Nesse sentido, apesar do estudo de Simões e La Rovere (2008), que analisaram o Brasil do ponto de vista da oferta de energia renovável, concluir que a matriz energética do país é, particularmente, limpa, sendo que a oferta interna de energia renovável, do país, é de 44,1\% (BRASIL, 2012a), o setor industrial ainda possui muitas das suas atividades dependentes de combustíveis fósseis. Como consequência, esse setor acaba agredindo o meio ambiente por emitir altíssimas concentrações de gases do efeito estufa (GEE), aumentando o aquecimento global, além de contribuir para a extensa extração de combustíveis na forma de petróleo e carvão.

Kolk e Pinkse (2004) afirmam que questões relacionadas à mudança do clima têm atraído, cada vez mais, a atenção das organizações nas últimas décadas. Esses autores indicam que as empresas 
enfrentam um crescimento gradual de desafios, atrelado, necessariamente, ao grau de adoção de combustíveis fósseis em seus produtos e processos produtivos.

Nesse contexto, o setor industrial de ferro-gusa e aço possui grande representatividade no consumo de energia no país, sendo responsável por cerca de $20 \%$ do consumo final de energia do setor industrial (BRASIL, 2012a), além de consumir elevadas quantidades de combustíveis fósseis em seus processos. A evolução no uso de combustíveis pelo setor industrial, de 2000 a 2010, é evidenciada na Tabela 1.

Verifica-se uma tendência de crescimento no uso de energéticos pelo setor no período de 2000 a 2008. Entretanto, o ano de 2009 apresentou um recuo no consumo de combustíveis, evidenciado pela crise financeira internacional, como já comentado.

De acordo com o Brasil (2012a), em 2011 o setor de ferro-gusa e aço apresentou 43,3\% de consumo de energia a partir do coque de carvão mineral e 10,9\% a partir do carvão mineral, como ilustrado na Figura 1.
Considerando que o setor de ferro-gusa e aço é o segundo maior consumidor de energia, no Brasil, e tem uma matriz energética extremamente dependente de combustíveis fósseis, o presente artigo visa responder à seguinte questão de pesquisa: existe possibilidade de redução da emissão de $\mathrm{CO}_{2}$ por meio da alteração da matriz energética do setor de ferro-gusa e aço?

Desse modo, tendo como base o conceito de produção sustentável, o presente artigo tem como objetivo analisar a possibilidade de redução de $\mathrm{CO}_{2}$ pelo setor industrial de ferro-gusa e aço, por meio do consumo de fontes energéticas mais limpas.

\section{Setor industrial de ferro-gusa e aço}

O ferro pode ser encontrado na natureza na forma de óxidos, carbonatos e sulfetos. Destes, os óxidos são os minérios que possuem maior percentual de ferro em massa, sendo encontrados, principalmente, na forma de hematita $\left(\mathrm{Fe}_{2} \mathrm{O}_{3}\right)$ ou de magnetita $\left(\mathrm{Fe}_{3} \mathrm{O}_{4}\right)$. Para a obtenção do ferro metálico a partir

Tabela 1. Estrutura de consumo do setor industrial - ferro-gusa e aço em $10^{3}$ tep.

\begin{tabular}{lccccccccccc}
\hline \multicolumn{1}{c}{ Fontes } & $\mathbf{2 0 0 1}$ & $\mathbf{2 0 0 2}$ & $\mathbf{2 0 0 3}$ & $\mathbf{2 0 0 4}$ & $\mathbf{2 0 0 5}$ & $\mathbf{2 0 0 6}$ & $\mathbf{2 0 0 7}$ & $\mathbf{2 0 0 8}$ & $\mathbf{2 0 0 9}$ & $\mathbf{2 0 1 0}$ & $\mathbf{2 0 1 1}$ \\
\hline Gás natural & 781 & 900 & 911 & 936 & 1.113 & 1.105 & 1.214 & 1.158 & 866 & 897 & 981 \\
Carvão mineral & 1.587 & 1.902 & 2.182 & 2.455 & 2.374 & 2.352 & 2.516 & 2.655 & 2.048 & 1.772 & 1.924 \\
Óleo diesel & 22 & 35 & 36 & 40 & 44 & 40 & 14 & 14 & 14 & 15 & 32 \\
Óleo combustível & 103 & 105 & 117 & 79 & 82 & 107 & 145 & 142 & 114 & 168 & 5 \\
Gás liquefeito de & 105 & 81 & 82 & 56 & 100 & 85 & 88 & 97 & 77 & 71 & 72 \\
petróleo & & & & & & & & & & & \\
Nafta & 0 & 0 & 0 & 0 & 0 & 0 & 0 & 0 & 0 & 0 & 0 \\
Querosene & 2 & 2 & 1 & 1 & 1 & 1 & 0 & 0 & 1 & 0 & 0 \\
Gás de coqueria & 891 & 879 & 972 & 1.037 & 1.016 & 980 & 1.039 & 1.065 & 1.011 & 1.250 & 1.353 \\
Gás canalizado & 0 & 0 & 0 & 0 & 0 & 0 & 0 & 0 & 0 & 0 & 0 \\
Coque de carvão & 6.221 & 6.582 & 6.470 & 6.574 & 6.067 & 5.763 & 6.320 & 6.289 & 4.969 & 7.153 & 7.657 \\
mineral & & & & & & & & & & & \\
Eletricidade & 1.200 & 1.289 & 1.382 & 1.452 & 1.397 & 1.452 & 1.579 & 1.602 & 1.279 & 1.613 & 1.714 \\
Carvão vegetal & 3.439 & 3.561 & 4.057 & 4.902 & 4.804 & 4.636 & 4.775 & 4.679 & 2.724 & 3.372 & 3.789 \\
Alcatrão/Outras sec. & 415 & 392 & 492 & 413 & 462 & 464 & 551 & 528 & 533 & 134 & 145 \\
petróleo & & & & & & & & & & & \\
Total & $\mathbf{1 4 . 7 6 7}$ & $\mathbf{1 5 . 7 2 9}$ & $\mathbf{1 6 . 7 0 1}$ & $\mathbf{1 7 . 9 4 5}$ & $\mathbf{1 7 . 4 5 9}$ & $\mathbf{1 6 . 9 8 5}$ & $\mathbf{1 8 . 2 4 0}$ & $\mathbf{1 8 . 2 2 9}$ & $\mathbf{1 3 . 6 3 6}$ & $\mathbf{1 6 . 4 4 5}$ & $\mathbf{1 7 . 6 7 2}$ \\
\hline
\end{tabular}

Fonte: Brasil (2012a).

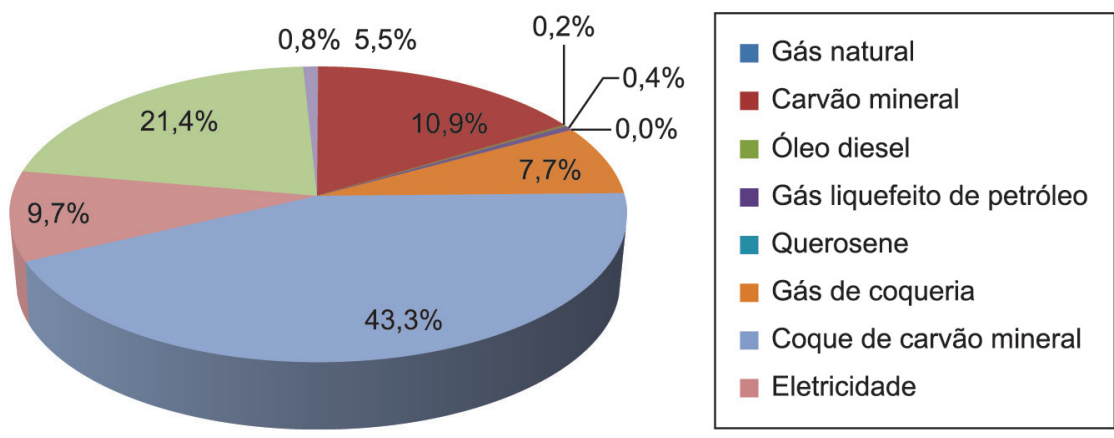

Figura 1. Consumo energético do setor ferro-gusa e aço em 2011. Fonte: Brasil (2012a). 
do minério de ferro, é necessário que este último sofra uma redução, ou seja, o oxigênio deve ser removido, em geral, combinando-se com o carbono (ROMEIRO, 1997).

A princípio, a maneira para obtenção de ferro ocorria, basicamente, a partir de uma mistura de minério de ferro com o carvão vegetal a sopro (ou entrada de ar natural). A queima do carvão é responsável por gerar calor e gases redutores $(\mathrm{CO})$, o que permite a redução dos óxidos de ferro e a produção de uma massa sólida de ferro com baixo teor de carbono, além de escória, que é matéria-prima para a fabricação de cimento. Esse material era, então, aquecido e forjado para obtenção das formas adequadas para a sua utilização (JACOMINO et al., 2002).

No entanto, segundo Jacomino et al. (2002), com o aparecimento de leis restringindo a devastação de florestas, impostas, principalmente, pelo governo inglês, a indústria tentou utilizar o carvão mineral em substituição ao carvão vegetal. No início, as dificuldades para conseguir seu amolecimento e cozimento dentro do forno inibiam sua utilização. Contudo, com a transformação do carvão mineral em coque, foi possível utilizá-lo no alto-forno. Assim, por volta de 1708 - 1709, na Inglaterra, o primeiro ferro-gusa era feito a partir do coque de carvão mineral, sendo, hoje, essa a maior fonte de energia do setor industrial de ferro-gusa e aço (BRASIL, 2012a).

Desse modo, Jacomino et al. (2002) afirmam que, para a produção do metal em alto forno, podem ser utilizados dois tipos de combustíveis, responsáveis também pelo papel de redutores: carvão vegetal ou coque. A opção pelo uso de carvão vegetal ou coque para a redução do minério de ferro é relacionada ao custo. De acordo com o trabalho de Uhlig, Goldemberg e Coelho (2008), o preço do coque é $19,0 \%$ mais baixo que o do carvão vegetal de origem nativa produzido legalmente e $29,7 \%$ que o de carvão vegetal de origem plantada. Já o preço do carvão vegetal de origem nativa produzido de forma ilegal varia entre 10 e $12 \%$ do preço do carvão vegetal produzido a partir de florestas plantadas.

Apesar da vantagem do coque em relação ao preço, esses autores afirmam, em contrapartida, que, como não há enxofre em sua composição, o carvão vegetal proporciona uma melhor qualidade do ferro-gusa e do aço produzido aumentando, consequentemente, o preço final do produto (UHLIG; GOLDEMBERG; COELHO, 2008).

Considerando isso, vale descrever melhor as etapas de produção do metal. Durante o processo de redução, no caso do carvão vegetal, os materiais carregados no alto-forno - minério de ferro, carvão vegetal e fundentes (quartzo, calcário, dolomita etc.) - transformam-se nos produtos: ferro-gusa (ou ferro de primeira fusão), escória, gás de alto-forno e poeira. A redução dos óxidos de ferro se processa à medida que a carga desce no interior do forno $\mathrm{e}$ os gases, resultantes da queima do carvão vegetal, sobem pela coluna de carga. Há um preaquecimento dos materiais e uma alteração na composição da carga. $\mathrm{O}$ oxigênio, que estava combinado com o ferro do minério, passa, sob a forma de óxidos de carbono, a fazer parte dos gases, deixando, assim, o ferro livre. Outras reações químicas e a fusão da ganga e dos fundentes acompanham o processo e formam a escória.

Vários combustíveis podem ser injetados nas ventaneiras do alto-forno em substituição ao carvão vegetal granulado, carregado pelo topo do reator. Entre eles estão os finos de carvão vegetal, o óleo, o alcatrão e o gás natural (JACOMINO et al., 2002).

Uma vez obtido o ferro-gusa, a etapa seguinte do processo é o refino. O ferro-gusa é levado para a aciaria, ainda em estado líquido, para ser transformado em aço, mediante queima de impurezas e adições. O refino do aço se faz em fornos a oxigênio ou elétricos (INSTITUTO..., 2012).

Finalmente, a terceira fase clássica do processo de fabricação do aço é a laminação. $\mathrm{O}$ aço, em processo de solidificação, é deformado mecanicamente e transformado em produtos siderúrgicos utilizados pela indústria de transformação, como chapas grossas e finas, bobinas, vergalhões, arames, perfilados, barras etc. (INSTITUTO..., 2012).

Portanto, nesse processo, podem ser produzidos aço ou ferro-gusa, sendo diferenciados pelo teor de carbono, que no aço é de até $2 \%$ e no ferro-gusa está em torno de $4 \%$ em massa (JACOMINO et al., 2002). No Brasil, a produção de ferro-gusa ocorre em dois tipos de instalações: em indústrias que produzem exclusivamente ferro-gusa, conhecidas como guseiras, e em siderúrgicas integradas ou semiintegradas, onde além do ferro-gusa são produzidos aço e subprodutos (UHLIG; GOLDEMBERG; COELHO, 2008).

De acordo com o Instituto de Aço Brasil (INSTITUTO..., 2012), o Brasil, é o maior produtor de aço bruto da América Latina, seguido do México e da Argentina, como é possível observar pela Figura 2, que ilustra a produção de aço bruto dos países da América Latina, em janeiro de 2012.

Vale ressaltar, ainda, que, segundo Jacomino et al. (2002), o Estado de Minas Gerais é o maior centro brasileiro de ferro-gusa em unidades independentes de produção, como é possível observar pela Tabela 2 . A produção se baseia, essencialmente, a partir do minério de ferro explorado no Quadrilátero Ferrífero. De acordo com este autor, a extensa produção de ferro-gusa do estado, aliado à produção de leite e derivados, ocasiona graves agressões à atmosfera $\mathrm{e}$ aos recursos hídricos. 
Porém, parte das agressões derivadas do setor de ferro-gusa e aço tende a diminuir. Souza (2011) relata que uma visão que parece estar se tornando consensual, entre os produtores de Minas Gerais, é que para o setor, principalmente as usinas de ferrogusa não integradas (Aquelas que não pertencem a empresas que atuam em toda a cadeia do aço. As perspectivas são mais favoráveis para as usinas integradas, porque o custo do gusa na fabricação do aço não é tão significativo quanto é o custo do minério e do carvão para as siderúrgicas que só fabricam gusa (SOUZA, 2011)), se recuperar da crise de 2008/2009, da qual ainda sofre consequências, são necessárias a aquisição e a formação de florestas para que se possa garantir uma fonte sustentável de carvão.

De acordo com Souza (2011), essa visão surgiu a partir do preço alto do minério de ferro e do carvão, devido, principalmente, à demanda chinesa, que fez com que os custos do carvão aumentassem para $65 \%$ na fabricação de gusa e os do minério representassem 20\%. Em 2011, a tonelada do carvão (tipo vegetal) estava em torno de $\mathrm{R} \$ 300$ e a de minério em torno de $\mathrm{R} \$ 150$.

No entanto, vale mencionar que pelo grande consumo energético e pelo alto grau de impactos

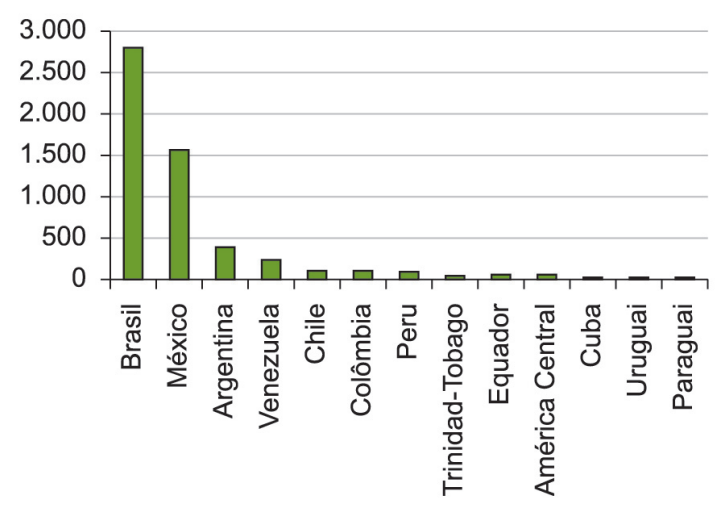

Figura 2. Produção de aço bruto da América Latina em jan./2012 (10 3 t). Fonte: IAB (INSTITUTO..., 2012). ambientais causados pelos grandes consumidores e emissores do setor industrial torna-se evidente a necessidade de ações visando a eficiência energética e de ações conjuntas da indústria e dos governos para o alcance de menor grau de emissão de GEE e de poluentes (INSTITUTO..., 2010).

No entanto, de acordo com a Confederação Nacional das Indústrias - CNI (2009), o estímulo a uma economia de baixa utilização de carbono demandará uma estrutura apropriada de incentivos, de regulação e de taxação. O conjunto de decisões depende de uma ação articulada que envolva o governo (regulações, taxação, negociações), setor privado (mudanças estruturais, decisões de investimento) e consumidores (comportamento). Para esses últimos, devem ser enfatizados os trabalhos de educação e informação sobre a intensidade do uso do carbono nos produtos consumidos.

A CNI (CONFEDERAÇÃO..., 2009) afirma, ainda, que o setor industrial brasileiro está ciente dos riscos do aquecimento global e do papel que lhe cabe na busca pela redução das emissões e nos esforços de adaptação. No entanto, apesar desse setor ter grande contribuição a oferecer no desenvolvimento de tecnologias e de soluções para adaptação, esse tema ainda não está enraizado nas estratégias das empresas. Persiste um baixo entendimento dos impactos, riscos e oportunidades. Com isso, a incorporação da preocupação com adaptação ainda é reduzida nas decisões de investimento das empresas do país.

Nesse sentido, vale ressaltar que a alteração do mix de combustíveis, ou seja, a substituição dos combustíveis mais intensivos em carbono por outros com menor intensidade, enquadra-se como uma das alternativas para a adaptação do setor industrial a uma economia de baixo carbono. Desse modo, amplia-se a importância deste trabalho, que se baseia na análise de oportunidades de redução do gás carbônico na indústria brasileira por meio da substituição de fontes não renováveis de energia por fontes renováveis, fornecendo, dessa forma, informações com relação aos benefícios de tal substituição.

Tabela 2. Distribuição regional da produção $\left(10^{3} \mathrm{t}\right)$.

JANEIRO/FEVEREIRO - 2012

ESTADO

AÇO BRUTO

\begin{tabular}{lrrrr}
\hline Minas Gerais & $1.848,1$ & 33,1 & $1.739,0$ & 32,8 \\
Rio de Janeiro & $1.637,5$ & 29,3 & $1.643,6$ & 31,0 \\
São Paulo & 853,7 & 15,3 & 684,1 & 12,9 \\
Espírito Santo & 884,1 & 15,8 & 728,3 & 13,7 \\
Outros & 365,8 & 6,5 & 509,8 & 9,6 \\
Total & $\mathbf{5 . 5 8 9 , 2}$ & $\mathbf{1 0 0 , 0}$ & $\mathbf{5 . 3 0 4 , 8}$ & $\mathbf{1 0 0 , 0}$ \\
\hline
\end{tabular}

LAMINADOS E

SEMIACABADOS P/ VENDAS

Fonte: IAB (INSTITUTO..., 2012). 
D e a c o r d o c o m o I P C C (INTERGOVERNMENTAL..., 2011), além de ter um grande potencial para mitigar as mudanças climáticas, as energias mais limpas, em especial as renováveis, podem fornecer benefícios mais amplos. Se implementadas corretamente, essas fontes de energia podem contribuir para um suprimento de energia seguro, para o acesso à energia, para reduzir os impactos negativos sobre o meio ambiente e saúde, e, por fim, para o desenvolvimento social e econômico. Além disso, vale lembrar que a substituição de combustíveis fósseis por fontes renováveis pode ser caracterizada como um projeto de MDL, que trata do comércio de créditos de carbono baseado em projetos de sequestro de carbono ou mitigação das emissões de $\mathrm{CO}_{2}$. Desse modo, a substituição da matriz energética do setor industrial de ferro-gusa e aço por energéticos mais limpos pode proporcionar benefícios nas três dimensões da sustentabilidade (ambiental, econômico e social).

\section{Método}

A partir do Balanço Energético Nacional, foi possível identificar os atuais combustíveis utilizados pelo setor industrial em estudo. A seguir identificaram-se os potenciais substitutos energéticos para o setor analisado, que serão utilizados como referência para a análise das reduções das emissões de $\mathrm{CO}_{2}$. O próximo passo foi a mensuração das emissões de $\mathrm{CO}_{2}$ considerando as fontes atualmente utilizadas e alterações hipotéticas da matriz energética pelos possíveis substitutos dessas fontes. Reitera-se que os valores foram calculados em escala anual e foi considerado todo o território nacional.

Destaca-se, no entanto, que a quantificação mais adequada para os combustíveis provenientes da biomassa deveria ser feita considerando as mudanças no uso do solo e florestas. O que o método top-down propõe é uma quantificação destes energéticos sem considerar a captura de $\mathrm{CO}_{2}$ desses combustíveis durante seu estágio de desenvolvimento característico. Logo, os resultados precisam ser interpretados com cautela. O método de quantificação é detalhado no próximo item.

Assim sendo, buscou-se qualificar, com relação ao impacto ambiental e suas emissões, os combustíveis utilizados nos processos produtivos do setor de ferro-gusa e aço.

Destaca-se que não são observadas, na indústria, emissões decorrentes do uso de energia elétrica, uma vez que essas emissões ocorrem durante a geração da mesma. No entanto, vale ressaltar que existe uma grande diversidade de formas de geração desse tipo de energia. Logo, as emissões da energia elétrica não foram abordadas no presente trabalho.

\subsection{Cálculo das emissões de $\mathrm{CO}_{2}$ : método top-down}

Parte superior do formulário

Existem dois métodos desenvolvidos pelo IPCC (1996) que permitem o cálculo de emissões de $\mathrm{CO}_{2}$ : o bottom-up e o top-down. Pela maior confiabilidade dos dados e menor complexidade para o levantamento destes, o método top-down foi o mais difundido (SIMÕES, 2003). De acordo com o Ministério da Ciência e Tecnologia - MCT (BRASIL, 2006), para a aplicação do método top-down do IPCC é necessário realizar a seguinte sequência de passos:

- Determinação do consumo aparente dos combustíveis, nas suas unidades de medida originais: neste trabalho, foi utilizado o consumo direto dos setores em estudo, com o objetivo de representar as emissões específicas dos segmentos estudados. Desse modo, foram utilizados o consumo dos combustíveis usados na produção industrial e o consumo total de cada setor. Esses dados foram encontrados no Balanço Energético Nacional.

- Conversão do consumo aparente para uma unidade de energia comum, terajoules (TJ): as quantidades dos combustíveis são expressas pelo BEN em toneladas equivalentes de petróleo (tep), para converter os valores do BEN para TJ, conforme recomendação do IPCC (INTERGOVERNMENTAL..., 1996), deve-se multiplicar $45,217 \times 10^{-3}$ pelo fator de correção, este é igual a 0,95 para os combustíveis sólidos e líquidos e 0,90 para os combustíveis gasosos (BRASIL, 2006).

- Transformação do consumo aparente de cada combustível em conteúdo de carbono, mediante a sua multiplicação pelo fator de emissão de carbono do combustível: nesta pesquisa, os valores utilizados para o fator de emissão foram aqueles indicados pelo MCT (BRASIL, 2006). Além disso, quando, ao invés de indicar o consumo de cada um dos energéticos pelo setor, o BEN (BRASIL, 2012a) indicava a somatória do consumo de energia de duas fontes, foi considerada, como fator de emissão, a média dos fatores dos dois combustíveis.

- Determinação da quantidade de carbono de cada combustível destinada a fins não energéticos e a dedução dessa quantidade do carbono contido no consumo aparente, para se computar o conteúdo real de carbono possível de ser emitido: foi utilizado como referência o consumo de fontes de energia dos setores 
industriais divulgados no BEN (BRASIL, 2012a), no qual todo combustível é considerado de uso energético. Logo, o único valor relevante para o cálculo das emissões foi do carbono não oxidado, explicado a seguir.

- Correção dos valores para se considerar a combustão incompleta do combustível, para se computar a quantidade de carbono realmente oxidada na combustão: a fração de carbono oxidada foi a recomendada pelo IPCC (INTERGOVERNMENTAL..., 1996): 0,98 para carvões, 0,99 para o petróleo e seus derivados, 0,995 para o gás natural. Para as demais fontes energéticas a fração de carbono oxidada foi a mesma utilizada pelo MCT (BRASIL, 2006).

- Conversão da quantidade de carbono oxidada em emissões de $\mathrm{CO}_{2}$ : foi obtida multiplicando-se as emissões em termos de carbono por 44/12. Onde 44 é o peso molecular do $\mathrm{CO}_{2}$ e 12 é o peso atômico do carbono (C).

A seguir são apresentados os resultados obtidos a partir da elaboração dos inventários de emissão de dióxido de carbono do setor de ferro-gusa e aço.

\section{Resultados e discussão}

A partir da técnica top-down, proposta pelo IPCC (1996), e com base no consumo de energéticos fornecidos pelo BEN (BRASIL, 2012a), procedeu-se com a quantificação das emissões atmosféricas de $\mathrm{CO}_{2}$ no setor industrial de ferro-gusa e aço, para o ano de 2011. Vale lembrar que as emissões por eletricidade não foram consideradas nas quantificações, pois dependem da forma de geração de energia (hidráulica, térmica, nuclear, eólica). Vale mencionar ainda que, para o fator de emissão do "Alcatrão/Outras sec. Petróleo" foi calculada uma média entre o fator de emissão do alcatrão $(25,8)$ e o fator de emissão de outros produtos secundários do petróleo (20).

As etapas necessárias para obtenção do resultado final foram dispostas nas Tabela 3 como apresentadas a seguir.

Reitera-se que os valores são calculados em escala anual e é considerado todo o território brasileiro. Assim sendo, foi possível elaborar a Figura 3, que apresenta a participação de cada combustível nas emissões de $\mathrm{CO}_{2}$ no setor industrial de ferro-gusa e aço.

Observa-se que, dos combustíveis mais utilizados no setor de ferro-gusa e aço, o coque de carvão mineral é o maior responsável pelas elevadas emissões atmosféricas de $\mathrm{CO}_{2}$ desse setor. $\mathrm{O}$ combustível emitiu 34,87 $\times 10^{6}$ toneladas (t) de $\mathrm{CO}_{2}$, correspondendo a $53,7 \%$ do total das emissões. O carvão vegetal contribui com 24,2\% (15,7 x $\left.10^{6} \mathrm{tCO}_{2}\right)$ das emissões nacionais do setor em estudo, seguido do carvão mineral, com 11,8\% (7,66 $\times 10^{6}$ t CO $\left._{2}\right)$. A emissão total de $\mathrm{CO}_{2}$, somadas às quantidades emitidas por todos os combustíveis utilizados, exceto pela eletricidade, foi de $64,9 \times 10^{6} \mathrm{t}$.

Vale ressaltar que, no caso de indústrias que produzem os próprios combustíveis renováveis, por meio da reposição da biomassa utilizada no processo produtivo, considera-se que não há emissões de gás carbônico. No entanto, tal característica de captura do $\mathrm{CO}_{2}$ não foi mensurada nos cálculos efetuados.

Sendo assim, segundo o MCT (BRASIL, 2006), as estimativas das emissões de $\mathrm{CO}_{2}$, para o carvão

Tabela 3. Etapas de quantificação das emissões de $\mathrm{CO}_{2}$ (2011).

\begin{tabular}{|c|c|c|c|c|c|}
\hline Combustível & $\begin{array}{c}\text { Consumo - tep } \\
\text { (1) }\end{array}$ & $\begin{array}{c}\text { Consumo }- \text { TJ } \\
\text { (2) }\end{array}$ & $\begin{array}{c}\text { Conteúdo } \\
\text { carbono (tC) } \\
(3) \\
\end{array}$ & $\begin{array}{c}\text { Emissão } \\
\text { carbono }(\mathrm{Gg} \mathrm{C}) \\
(5)\end{array}$ & $\begin{array}{c}\text { Emissão } \mathrm{CO}_{2} \\
\left(1^{6} \mathrm{t} \mathrm{CO}_{2}\right) \\
(6)\end{array}$ \\
\hline Gás natural & $980.540,00$ & $39.903,37$ & $610.521,55$ & 607,47 & 2,23 \\
\hline Carvão mineral & $1.924 .093,08$ & $82.651,63$ & $2.132 .412,08$ & $2.089,76$ & 7,66 \\
\hline Óleo diesel & $32.122,75$ & $1.379,87$ & $27.873,36$ & 27,59 & 0,10 \\
\hline Óleo combustível & $5.488,82$ & 235,78 & $4.974,93$ & 4,93 & 0,02 \\
\hline GLP & $72.278,71$ & $3.104,81$ & $53.402,82$ & 52,87 & 0,19 \\
\hline Nafta & 0,00 & 0,00 & 0,00 & 0,00 & 0,00 \\
\hline Querosene & 0,00 & 0,00 & 0,00 & 0,00 & 0,00 \\
\hline Gás de coqueria & $1.352 .976,08$ & $55.059,77$ & $1.002 .087,77$ & 997,08 & 3,66 \\
\hline Gás canalizado & 0,00 & 0,00 & 0,00 & 0,00 & 0,00 \\
\hline Coque de carvão mineral & $7.657 .084,77$ & $328.918,88$ & $9.703 .107,01$ & $9.509,04$ & 34,87 \\
\hline Eletricidade & $1.714 .228,77$ & $73.636,67$ & - & & 0,00 \\
\hline Carvão vegetal & $3.788 .730,89$ & $162.749,29$ & $4.866 .203,84$ & $4.282,26$ & 15,70 \\
\hline $\begin{array}{l}\text { Alcatrão/Outras sec. } \\
\text { petróleo }\end{array}$ & $144.737,74$ & $6.217,38$ & $142.377,91$ & 139,53 & 0,51 \\
\hline
\end{tabular}




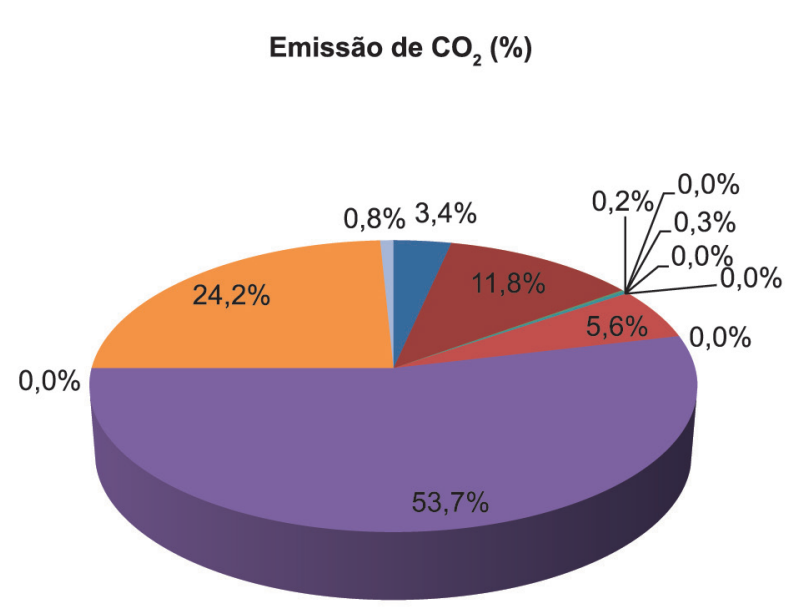

- Gás natural
Carvão mineral
Óleo diesel
Óleo combustível
Gás liquefeito de petróleo
Nafta
Querosene
Gás de coqueria
Gás canalizado
Coque de carvão mineral
Eletricidade
Carvão vegetal
Alcatrão/outras sec. petróleo

Figura 3. Emissões de $\mathrm{CO}_{2}$ por combustível no setor de ferro-gusa e aço (\%).

vegetal, devem ser incluídas no inventário nacional de emissões do sistema energético, apenas a título de informação, sem serem adicionadas às emissões dos combustíveis fósseis. Isso porque as emissões derivadas do consumo do carvão vegetal são objeto do módulo metodológico do IPCC, Uso do Solo e Manejo Florestal, onde será determinado o balanço entre o carbono emitido pela biomassa removida e o carbono absorvido durante o crescimento de novas plantas.

Diante disso, pela análise dos resultados obtidos, sabe-se que o carvão vegetal teve amplo uso na indústria brasileira. Uma vez que o setor industrial possui tecnologia e capacidade operacional em utilizá-lo, o carvão vegetal apresenta-se com um potencial substituto renovável para os combustíveis fósseis. Além disso, uma vez que os combustíveis não renováveis, carvão mineral e coque de carvão mineral, possuem um consumo elevado e corresponderam a 65,5\% das emissões de $\mathrm{CO}_{2}$, em 2011, percebe-se que a substituição desses energéticos traria grandes modificações à quantidade de dióxido de carbono emitido na atmosfera por esse setor industrial.

A partir dos dados de consumo energético, também, foi realizada a quantificação das emissões de $\mathrm{CO}_{2}$ supondo a mudança da matriz energética desse setor para comparar as emissões. De acordo com BEN (BRASIL, 2012a), o consumo total para o ano de 2011 foi de $15.958 \times 10^{3}$ tep. Desconsiderou-se, nesse total, o consumo por eletricidade, o qual não é o foco da pesquisa. Fixando esse consumo para cada combustível utilizado na indústria (etapa 1 do método top-down), é possível estimar quanto se emitiria, caso toda a matriz energética fosse substituída por esse combustível. Assim, a Tabela 4 mostra o resultado obtido para as emissões de $\mathrm{CO}_{2}$ de cada combustível, como se esse fosse utilizado como único suprimento para toda a demanda energética do setor.
Tabela 4. Emissões de $\mathrm{CO}_{2}$ considerando consumo total do setor por apenas um combustível.

\begin{tabular}{lc}
\hline \multicolumn{1}{c}{ Combustível } & $\begin{array}{r}\text { Emissão de CO} \mathbf{~}_{2} \\
\left(\mathbf{1 0}^{\mathbf{6}} \mathbf{t} \mathbf{C O}_{\mathbf{2}}\right)\end{array}$ \\
\hline Gás natural & 36,25 \\
Carvão mineral & 63,55 \\
Óleo diesel & 50,26 \\
Óleo combustível & 52,50 \\
Gás liquefeito de petróleo & 42,80 \\
Nafta & 47,28 \\
Querosene & 48,77 \\
Gás de coqueria & 43,12 \\
Gás canalizado & 45,02 \\
Coque de carvão mineral & 72,66 \\
Eletricidade & - \\
Carvão vegetal & 66,13 \\
Alcatrão/Outras sec. Petróleo & 56,41 \\
\hline
\end{tabular}

Nota-se que os combustíveis que mais emitem gás carbônico, para o mesmo consumo de energia são, respectivamente, o coque de carvão mineral, o carvão vegetal e o carvão mineral. Analisando somente as emissões de $\mathrm{CO}_{2}$, percebe-se, ainda, que, dentre os combustíveis analisados, os gasosos se mostraram menos poluentes. É possível observar que o gás natural emite menos da metade do $\mathrm{CO}_{2}$ emitido pelo coque de carvão mineral.

Isso ocorre devido ao fator de conversão e ao fator de emissão de carbono. O fator de conversão considera, em seu valor, a conversão da energia de PCS para PCI. Para tanto, deve-se multiplicar o consumo energético por 0,95 , para combustíveis sólidos e líquidos, e por 0,90, para combustíveis gasosos. Isso significa que $10 \%$ do calor liberado pelos gases são utilizados como calor latente para 
que a água vaporize. No caso dos combustíveis sólidos, esse valor é menor, o que resulta em maior quantidade de energia liberada na forma de calor e maiores valores de $\mathrm{CO}_{2}$ gerado.

Mais considerável do que o fator de conversão é o fator de emissão de carbono. Nos combustíveis gasosos esse valor, que é multiplicado pelo consumo, em TJ, varia de 15,3 (gás natural) a 17,2 (gás liquefeito do petróleo - GLP). No caso dos combustíveis sólidos ele chega a 29,9 (no caso do carvão vegetal). Vale lembrar que quanto menor o fator de emissão de carbono menor é o valor de gás carbônico emitido.

A partir do consumo total real do setor, com sua matriz energética diversificada, e considerando, também, a quantidade de $\mathrm{CO}_{2}$ emitida pelos combustíveis, supondo que os mesmos sejam utilizados na indústria de ferro-gusa e aço de forma exclusiva, elaborou-se a Figura 4, a seguir.

Observa-se que, se fosse possível utilizar apenas um combustível na indústria de ferro-gusa e aço para suprir sua demanda energética, as emissões de $\mathrm{CO}_{2}$ seriam menores para os combustíveis gasosos, líquidos e o alcatrão e outras fontes secundárias do petróleo. Sendo que para o carvão mineral as emissões estariam bem próximas das emitidas no período em estudo. Esses resultados indicam um potencial significativo para reduzir a emissão de $\mathrm{CO}_{2}$ pelo setor industrial de ferro-gusa e aço, por meio da utilização do gás natural, em substituição aos demais combustíveis fósseis, quando possível.

Nota-se, ainda, que, se mantido o mesmo consumo energético, o coque de carvão mineral é o maior emissor de gás carbônico, seguido do carvão vegetal. Entretanto, o método top-down do IPCC (1996) não considera em seus cálculos a condição de combustível renovável do carvão vegetal, que absorve $\mathrm{CO} 2$ da atmosfera no desenvolvimento da planta que gera a lenha necessária para produzir o carvão. Os combustíveis de origem renovável, como já mencionado, não geram emissões líquidas, e as emissões associadas à parcela não renovável são incluídas no setor de Mudança do Uso da Terra e Florestas. Portanto, o uso do carvão vegetal, ao invés de um combustível fóssil, pode contribuir para a redução do aquecimento global desde que o mesmo seja proveniente de matas de reflorestamento destinadas para a atividade industrial.

O coque de carvão mineral, diferente do carvão vegetal, não é um combustível renovável, ou seja, sua reposição é inviável em curto período de tempo. Assim sendo, sua oferta como energético é limitada, o que pode ocasionar falta de suprimento na indústria em longo prazo. Da mesma forma, o coque de carvão mineral não irá absorver o $\mathrm{CO}_{2}$ emitido, fazendo com que sua concentração na atmosfera aumente ainda mais, contribuindo para a elevação do efeito estufa com consequências em nível global. O mesmo pode ser dito do carvão mineral e dos outros combustíveis não renováveis, que, embora emitam menos gás carbônico para suprir a mesma demanda energética, possuem suas reservas naturais limitadas em longo período de tempo.

Outra suposição possível de ser realizada é a substituição de uma fonte de energia por outra. $\mathrm{O}$ mais importante nessa etapa é avaliar os principais

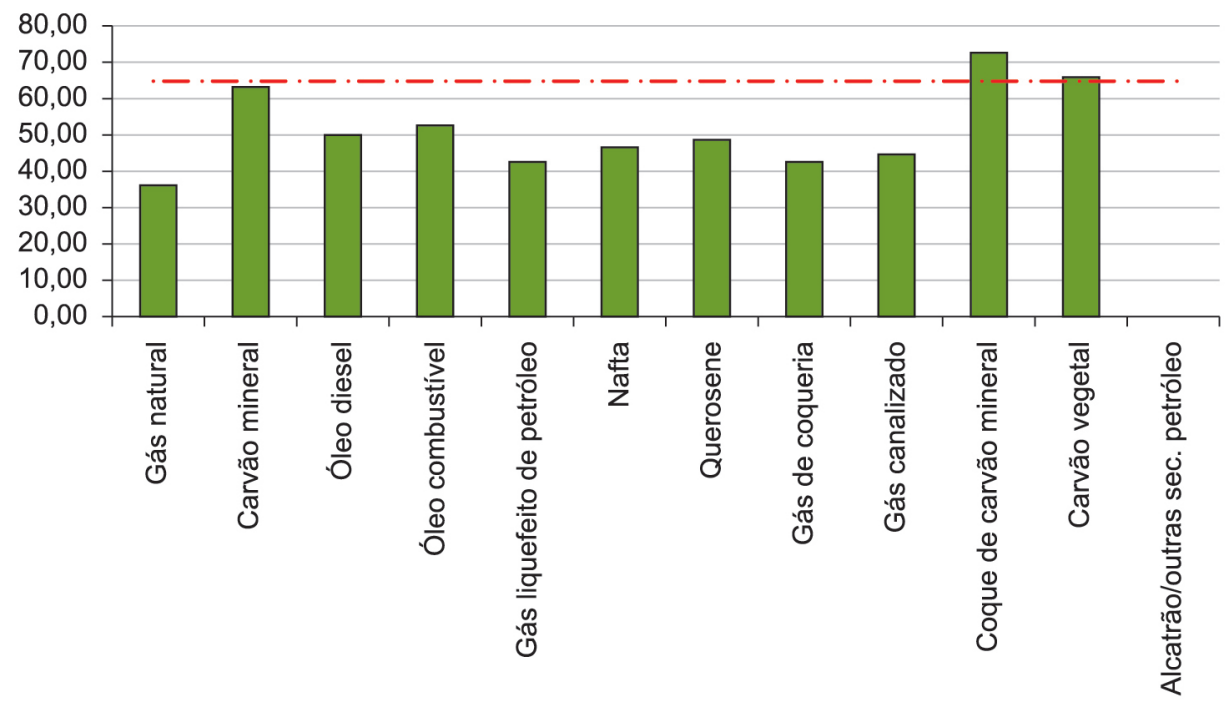

$\square$ Emissões potenciais de gás carbônico .-... Valor real emitido de gás carbônico

Figura 4. Emissões de $\mathrm{CO}_{2}$ supondo o consumo de apenas um combustível (em $10^{6} \mathrm{t}$ de $\mathrm{CO}_{2}$ ). $\mathrm{O}$ consumo de energia por eletricidade não foi computado na estimativa do valor real emitido. 
combustíveis utilizados na indústria e estimar as emissões de $\mathrm{CO}_{2}$ de cada um deles, supondo que o mesmo seja o principal energético utilizado no setor. Assim, é possível implementar políticas que incentivem o uso de um combustível em substituição a outro mais poluente.

De acordo com o BEN (BRASIL, 2012a), o coque de carvão mineral, o carvão vegetal e o carvão mineral são responsáveis por $75,7 \%$ da demanda de combustíveis do setor. Os mesmos emitiram, em 2011, 89,7\% de todo gás carbônico lançado na atmosfera pelo setor industrial brasileiro. Dessa forma, realizam-se suposições para o caso de um desses combustíveis ser utilizado considerando que os outros dois sejam completamente substituídos pelo primeiro. Tais situações serão descritas a seguir.

Supondo a substituição do carvão mineral e vegetal pelo coque de carvão mineral, mantendo-se o uso das demais fontes energéticas, as emissões totais de $\mathrm{CO}_{2}$ do setor industrial passariam de 64,9 x $10^{6}$ para $67,6 \times 10^{6} \mathrm{t}$ de $\mathrm{CO}_{2}$. No caso da utilização do carvão vegetal ao invés do carvão mineral e do coque de carvão mineral, as emissões diminuiriam para $62,1 \times 10^{6} \mathrm{t}$ de $\mathrm{CO}_{2}$. E, por fim, se o carvão mineral fosse adotado como principal combustível, em substituição do coque e do carvão vegetal, as emissões de $\mathrm{CO}_{2}$ diminuiriam para 59,95 x $10^{6} \mathrm{t}$.

Para melhor comparação dos resultados, a Figura 5 mostra, a seguir, as emissões de $\mathrm{CO}_{2}$, considerando o uso do coque de carvão mineral, do carvão vegetal ou do carvão mineral como principais combustíveis.

A partir da Figura 5, fica evidente que o combustível que emite menos gás carbônico e que melhor contribuiria para a redução das emissões no processo industrial é o carvão mineral. O coque de carvão mineral mostrou-se o maior poluente, seguido pelo carvão vegetal. Vale salientar, novamente, que o método utilizado nessa pesquisa não considera o fator de combustível renovável do carvão vegetal, o que garante que o $\mathrm{CO}_{2}$ seja reposto em sua forma orgânica e em oxigênio.

Quando se afirma que o carvão vegetal repõe o $\mathrm{CO}_{2}$ emitido na atmosfera em sua cadeia produtiva, refere-se ao carvão vegetal obtido de áreas reflorestadas e certificadas. A derrubada de florestas nativas para fins energéticos, ao contrário, desmataria a vegetação nativa, comprometendo a capacidade do carvão vegetal em contribuir para a redução do efeito estufa.

Assim sendo, mesmo o carvão mineral sendo indicado como menor emissor de GEE, o mesmo não reduz o gás carbônico da atmosfera num ritmo compatível com o desenvolvimento humano, contribuindo com o aquecimento global.

Diante do apresentado, pode-se concluir que a remoção do coque de carvão mineral e do carvão mineral na indústria de ferro-gusa e aço, no Brasil, é ambientalmente viável para a introdução do carvão vegetal.

No entanto, vale lembrar que o setor de gusa, por décadas, se abasteceu de carvão de fontes ilegais, produzidos a partir da derrubada indiscriminada de matas nativas. Porém, no país, a derrubada de florestas nativas para fins industriais, energéticos ou qualquer outra exploração, econômica ou não, sem licença ou em desacordo com as determinações legais, de acordo com o artigo 46 do Decreto n. $6.514 / 08$, é uma atividade que não é mais permitida, acarretando uma multa de $\mathrm{R} \$ 500,00$ (quinhentos reais), por metro cúbico de carvão-mdc. Vale citar, ainda, que o artigo 34 do Novo Código Florestal - Lei n. 12.651, de 25 de maio de 2012, afirma que as empresas industriais que utilizam grande quantidade de matéria-prima florestal são obrigadas a elaborar e implementar o Plano de Suprimento Sustentável - PSS, a ser submetido à aprovação do órgão competente do Sisnama (Sistema

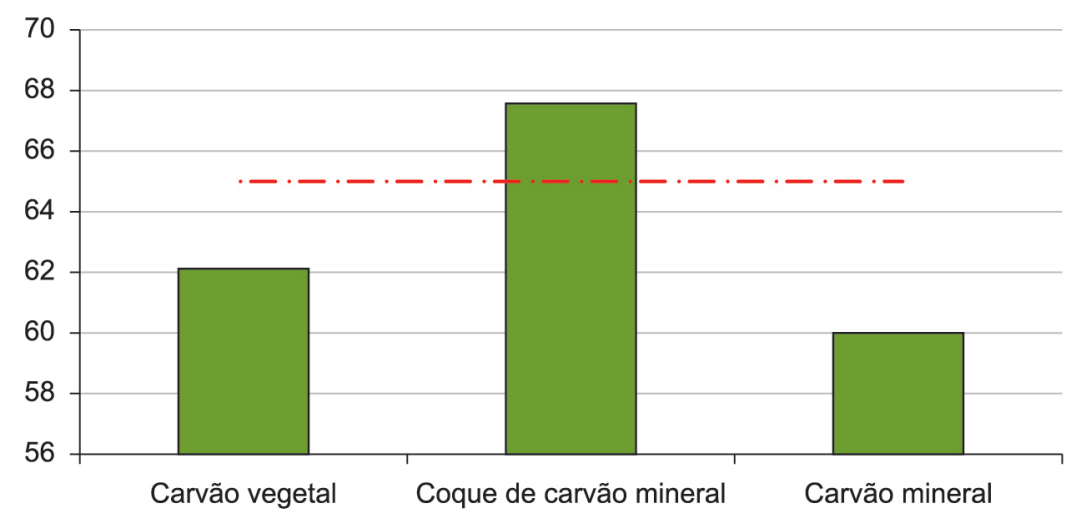

Emissões potenciais de gás carbônico .-.-. Valor real emitido de gás carbônico

Figura 5. Emissões totais de $\mathrm{CO}_{2}$ supondo substituição de dois combustíveis sólidos (em $10^{6} \mathrm{t}$ de $\mathrm{CO}_{2}$ ). 
Nacional do Meio Ambiente). Além disso, o PSS de empresas siderúrgicas, metalúrgicas ou outras que consumam grandes quantidades de carvão vegetal ou lenha estabelecerá a utilização exclusiva de matéria-prima oriunda de florestas plantadas ou de PMFS (Plano de Manejo Florestal Sustentável) e será parte integrante do processo de licenciamento ambiental do empreendimento (BRASIL, 2012b).

No entanto, vale lembrar que se ambientalmente o carvão vegetal é mais vantajoso, em termos econômicos o preço do coque é inferior. Desse modo, salienta-se a importância de incentivos do governo para a adoção do carvão vegetal como fonte energética para o processo produtivo do setor de ferro-gusa e aço, reduzindo, assim, os custos de conversão para esse tipo de fonte energética, que proporciona melhores benefícios ambientais.

Igualmente, ressalta-se a importância de uma política de incentivo para o gás natural. Os benefícios ambientais da utilização do gás natural como combustível, na indústria, ficaram evidentes a partir dos inventários realizados. Os mesmos indicaram um potencial significativo para reduzir as emissões de dióxido de carbono dos setores de ferro-gusa e aço por meio da utilização desse energético em substituição aos demais combustíveis fósseis. Além disso, as recentes descobertas de reservas proporcionam uma excelente perspectiva de expansão da oferta desse energético.

Vale mencionar, ainda, que, de acordo com Calou (2013), a expansão do mercado de gás permite a atração de outros supridores, além da Petrobras, o que traria benefícios à indústria e demais consumidores. Um forte aliado nessa expansão seria a inserção de térmicas no sistema elétrico brasileiro, pois, além de trazer segurança energética, são ótimas âncoras para a expansão dos sistemas de distribuição de gás, ainda muito tímidos no país.

Destaca-se que o Brasil tem demonstrado capacidade para adotar e efetivamente implementar políticas energéticas e tecnologias inovadoras, como exemplificado pelo programa do Proálcool, e os esforços para aumentar a eficiência no uso da eletricidade. Esses esforços envolveram um compromisso de longo prazo do governo; um conjunto abrangente de políticas para superar barreiras técnicas, institucionais e de mercado; e uma participação ativa do setor privado (GELLER et al., 2004). Uma estratégia semelhante poderia ser usada para implementar com sucesso um conjunto de políticas para incentivar o uso do carvão vegetal e outras fontes renováveis pela indústria, com os devidos cuidados, de modo a não comprometer outros aspectos ou setores do país, como o de produção de alimentos ou, ainda, de biocombustíveis.

\section{Conclusão}

Este trabalho permitiu analisar a estrutura de consumo do setor industrial de ferro-gusa e aço e pode ser uma ferramenta importante para auxiliar no desenvolvimento de planos e programas que compõem as políticas energéticas voltadas para o setor industrial. A comparação do nível de emissão do coque de carvão mineral e do carvão mineral com os seus possíveis substitutos permitiu concluir que, devido à caracterísica de combustível renovável do carvão vegetal, a remoção do coque de carvão mineral e do carvão mineral na indústria de ferrogusa e aço, no Brasil, é ambientalmente viável para a introdução do carvão vegetal, desde que este seja proveniente de matas de reflorestamento destinadas à indústria. Caso contrário, esse energético é um dos maiores emissores de $\mathrm{CO}_{2}$ do setor.

Vale mencionar, porém, que esse trabalho não considerou as emissões provenientes do transporte e da extração dos combustíveis analisados. Para a expansão da biomassa para geração de energia, ainda, deve ocorrer o gerenciamento das demandas competitivas da produção de alimentos e preservação das matas nativas. Desse modo, destaca-se como possibilidade de futuros trabalhos a análise do impacto da demanda de carvão vegetal oriundo de reflorestamento, considerando as atuais áreas destinadas a esse fim, além do risco de maior desmatamento e concorrência com a produção de alimentos.

É importante ressaltar, também, que este estudo não contemplou a demanda financeira que a substituição dos combustíveis na fábrica de ferrogusa e aço poderia exigir. Variações nos preços dos combustíveis podem contribuir na preferência pelo uso do carvão mineral ou coque de carvão mineral e, até mesmo, impedir o uso do carvão vegetal e de outros combustíveis menos poluentes. Desse modo, evidencia-se a possibilidade de futuros trabalhos que contemplem a análise econômica dessa substituição energética a fim de comprovar a sua viabilidade.

Apesar de este trabalho destacar o carvão vegetal como energético ambientalmente viável para os setores analisados, ressalta-se que não é o intuito desta pesquisa incentivar a utilização de uma única fonte de energia por determinado setor industrial. Tal procedimento comprometeria, entre outros aspectos, a segurança energética do setor. Além disso, ressalta-se a possibilidade de utilizar outros procedimentos para a mitigação das emissões no setor em estudo, como medidas de eficiência energética, por meio de tecnologias que possam reduzir o consumo de energia no processo, mantendo o mesmo nível de produção; e de técnicas de captura e estocagem de carbono (CAC).

Entretanto, destaca-se que a utilização do carvão vegetal e outras fontes renováveis, também, resultaria 
numa redução de GEE. A redução dessas emissões de GEE poderia resultar em um ganho financeiro razoável para as empresas, caso elas promovessem um projeto de Mecanismo de Desenvolvimento Limpo para Gerar Créditos de Carbono."

Vale mencionar, ainda, que a análise realizada neste trabalho, além de projetos relacionados à eficiência energética, pode ser replicada a outros setores industriais. Se essas medidas forem aplicadas a todos os setores, será possível reduzir grande parte da poluição gerada pelas atividades industriais, contribuindo assim para um futuro melhor para a sociedade.

No entanto, apesar do potencial do Brasil para o uso de energias renováveis, vale salientar a importância de incentivos do governo para concretizar as mudanças na estrutura de consumo de energia, reduzindo, dessa forma, os custos de conversão para as novas fontes de energia. Também é importante maior controle por parte dos órgãos de controle ambiental e dos consumidores, a fim de incentivar a prática de processos industriais menos poluentes.

Nesse sentido, reitera-se que, para a produção de ferro-gusa e aço ambientalmente viáveis, deverão ser realizadas parcerias do tipo público-privado e aumentar a renovabilidade na produção de lenha e carvão vegetal com controle da matéria-prima. Reitera-se, dessa forma, a importância em diminuir o consumo de matéria-prima proveniente da floresta nativa na produção de lenha e carvão vegetal com leis que sejam efetivas e inibam crimes ambientais.

\section{Referências}

BRASIL. Ministério da Ciência e Tecnologia - MCT. Emissões de dióxido de carbono por queima de combustíveis: abordagem top-down. Brasília, 2006. Disponível em: <http://www.mct.gov.br>. Acesso em: 5 nov. 2010.

BRASIL. Ministério de Minas e Energia - MME. Balanço Energético Nacional (BEN) 2012: Ano-Base 2011. Brasília. Disponível em: <http://www.mme.gov.br/ $\mathrm{mme} / \mathrm{menu} /$ todas_publicacoes.html>. Acesso em: 19 nov. 2012a.

BRASIL. Palácio do Planalto. Legislação: conheça o material legislativo produzido no Brasil. Brasília. Disponível em: <http://www2.planalto.gov.br/ presidencia/legislacao>. Acesso em: 21 ago. 2012b.

BRASIL. Ministério do Meio Ambiente - MMA. Convenção-Quadro das Nações Unidas sobre Mudança do Clima (UNFCCC). Brasília. Disponível em: <http://www.mma.gov.br/clima/convencao-dasnacoes-unidas $>$. Acesso em: 10 out. 2010.

CONFEDERAÇÃO NACIONAL DA INDÚSTRIA - CNI. Mudança do clima: uma contribuição da indústria. Brasília, 2009. Disponível em: <http://www.cni.org. br>. Acesso em: 8 set. 2011.
FREITAS, L. C.; KANEKO, S. Decomposition of $\mathrm{CO}_{2}$ emissions change from energy consumption in Brazil: Challenges and policy implications. Energy Policy, v. 39, 2011, p. 1495-1504. http://dx.doi.org/10.1016/j. enpol.2010.12.023

GELLER, H., R. et al. Policies for advancing energy efficiency and renewable energy use in Brazil. Energy Policy, v. 32, n. 12, p.1437-1450, 2004. http://dx.doi. org/10.1016/S0301-4215(03)00122-8

GLAVIC, P; LUKMAN, R. Review of sustainability terms and their definitions. Journal of Cleaner Production, v. 15, p. 1875-1885, 2007. http://dx.doi.org/10.1016/j. jclepro.2006.12.006

GOLDEMBERG, J.; MOREIRA, J. R. Política energética no Brasil. Estudos Avançados, v. 19, n. 55, p. 215-228, 2005. http://dx.doi.org/10.1590/ S0103-40142005000300015

INSTITUTO AÇO BRASIL - IAB. Número de mercado: estatísticas. 2012. Disponível em: <http://www. acobrasil.org.br/site/portugues/numeros/estatisticas. asp> Acesso em: 31 mar. 2012.

INSTITUTO DE PESQUISA ECONÔMICA E APLICADA - IPEA. Sustentabilidade Ambiental no Brasil: biodiversidade, economia e bem-estar humano. Brasília, 2010.

INTERGOVERNMENTAL PANEL ON CLIMATE CHANGE - IPCC. Climate Change 2007: Mitigation of Climate Change. Cambridge: Cambridge University Press, 2007. http://dx.doi.org/10.1017/ CBO9780511546013

INTERGOVERNMENTAL PANEL ON CLIMATE CHANGE - IPCC. IPCC Guidelines for National Greenhouse Gas Inventories. London, 1996. (Reporting Instructions, v. 1)

INTERGOVERNMENTAL PANEL ON CLIMATE CHANGE - IPCC. Renewable Energy Sources and Climate Change Mitigation. Cambridge: Cambridge University Press, 2011. (Special Report). Disponível em: <http://srren.ipcc-wg3.de/report>. Acesso em: 9 set. 2011.

JACOMINO, V. M. F. et al. Controle ambiental das indústrias de ferro-gusa em altos-fornos a carvão vegetal. Belo Horizonte: Projeto Minas Ambiente, 2002.

KOLK, A.; PINKSE, J. Market strategies for climate change. European Management Journal, v. 22, n. 3, p. 304-314, 2004. http://dx.doi.org/10.1016/j. emj.2004.04.011

LIOR, N. The current status and possible sustainable paths to energy "generation" and Use. Nuclear \& Renewable Energy Conference (INREC), 2010 1st International. Amman, 2010. p. 1-19. http://dx.doi. org/10.1109/INREC.2010.5462556

NIU, S. et al. Economic growth, energy conservation and emissions reduction: A comparative analysis based on panel data for 8 Asian-Pacific countries. Energy Policy, v. 39, n. 4, p. 2121-2131, 2011. http://dx.doi. org/10.1016/j.enpol.2011.02.003

PAZ, L. R. L.; SILVA, N. F.; ROSA, L. P. The paradigm of sustainability in the Brazilian energy sector. Renewable and Sustainable Energy Reviews, v. 11, 
n. 7, p. 1558-1570, 2007. http://dx.doi.org/10.1016/j. rser.2005.12.005

ROMEIRO, S. B. B. Química na Siderurgia. Porto Alegre: UFRGS, 1997.

SILVA, F. I. A.; GUERRA, S. M. G. Analysis of the energy intensity evolution in the Brazilian industrial sector - 1995 to 2005. Renewable and Sustainable Energy Reviews, v. 13, n. 9, p. 2589-2596, 2009. http:// dx.doi.org/10.1016/j.rser.2009.01.003

SIMÕES, A. F. O Transporte aéreo brasileiro no contexto de mudanças climáticas globais: emissões de $\mathrm{CO}_{2}$ e alternativas de mitigação. 2003. 228 f. Tese (Doutorado)-COPPE, Universidade Federal do Rio de Janeiro, Rio de Janeiro, 2003.
SIMÕES, A. F.; LA ROVERE, E. L. Energy sources and global climate change: the Brazilian case. Energy Sources Part A: Recovery, Utilization \& Environmental Effects, v. 30, n. 14-15, p. 1327-1344, 2008. http://dx.doi.org/10.1080/15567030801928854

SOUZA, M. M. Produtores de ferro-gusa enfrentam sua pior crise. Valor Econômico, 20 out. 2011. Disponível em: <http://www.power.inf.br/site/ todas-as-noticias-de-geral/8596-produtores-de-ferrogusa-enfrentam-sua-pior-crise $>$. Acesso em: 20 out. 2011.

UHLIG, A.; GOLDEMBERG, J.; COELHO, S. T. O uso de carvão vegetal na indústria brasileira e o impacto sobre as mudanças climáticas. Revista Brasileira de Energia, v. 14, n. 2, p. 67-85, 2008. 